\title{
IMPACTOS ECONÔMICOS DA IMPLANTAÇÃO DE ATERROS SANITÁRIOS INDIVIDUAIS NOS MUNICÍPIOS BRASILEIROS
}

\author{
${ }^{1}$ A. O. Brandão e ${ }^{2}$ G. N. Silva \\ ${ }^{1}$ CESMAC-AL e ${ }^{2}$ Limpel Limpeza Urbana Ltda \\ glauber@limpel.com.br
}

Artigo submetido em março/2011 e aceito em junho/2011

\section{RESUMO}

A Política Nacional de Resíduos Sólidos (Lei Federal no 12.305 /2010) proíbe a disposição de resíduos sólidos em lixões e recomenda que até 2014 os municípios brasileiros realizem ações de recuperação ambiental nas áreas degradadas por esses depósitos e passem a dispor seus resíduos em aterros sanitários, conjuntamente com outras ações de gestão de resíduos sólidos. Diante desse novo desafio, torna-se necessário que os governos (Federal, Estadual e Municipal) realizem uma análise do impacto econômico dessa medida sobre as finanças públicas e crie alternativas para reduzir o custo da disposição dos resíduos sólidos urbanos de forma adequada. Partindo desse pressuposto, este trabalho analisa através de informações primárias de população, Produto Interno Bruto, custos de disposição de resíduos em aterros, e com uso de sistemas de informações geográficas, o impacto dessa solução nas finanças de cada município brasileiro. Como conclusão, é demonstrada a inviabilidade econômica de se adotar aterros individuais e quais as regiões que necessitam de maior apoio governamental para adotar as soluções exigidas pela nova política.

PALAVRAS-CHAVE: Política Nacional de Resíduos Sólidos, aterro sanitário, viabilidade econômica.

\section{ECONOMIC IMPACTS OF THE PERSONAL IMPLEMENTATION OF SANITARY LANDFILLS IN BRAZILIAN CITIES}

\section{ABSTRACT}

The National Policy on Solid Waste (Federal Law No. 12,305 / 2010) prohibits the disposal of solid waste in landfills. Facing this new challenge, it is necessary that the governments (federal, state and local) to conduct an analysis of the economic impact of this measure on public finances and create alternatives to reduce the cost of disposal of these wastes properly. Based on municipality and with subsequent application of mathematical modeling results in a geographic information system. In conclusion we demonstrate the economic infeasibility of adopting individual landfills and which regions need more government support to adopt the solutions required by the new policy. this assumption, we analyze the cost of disposal in landfills in the country and its impact on GDP of each

KEY-WORDS: National Policy on Solid Wastes, landfill, economic viability. 


\section{IMPACTOS ECONÔMICOS DA IMPLANTAÇÃO DE ATERROS SANITÁRIOS INDIVIDUAIS NOS MUNICÍPIOS BRASILEIROS}

\section{INTRODUÇÃO}

Com a promulgação da Política Nacional de Resíduos Sólidos (Lei Federal no $12.305 / 2010$ ) e a respectiva proibição da disposição de resíduos sólidos em vazadouros sem controle (comumente conhecidos como lixões) tornou-se imperativo analisar a viabilidade econômica de soluções ambientais para a correta disposição e tratamento de resíduos sólidos para as cidades brasileiras. Dentre as medidas adotadas encontra-se a adoção de aterros sanitários. Contudo, qual o impacto nas finanças municipais decorrente dessa solução, caso a mesma seja utilizada para atender os municípios de forma individualizada e não na forma de consórcio como prevê a Política? Partindo dessa hipótese adotou-se uma metodologia para análise dos custos desse tipo de empreendimento e posterior modelagem matemática e representação sob a forma de mapa de modo a avaliar o impacto financeiro da adoção das soluções não-consorciadas para os municípios brasileiros.

\section{RERERENCIAL TEÓRICO}

Segundo a NBR 10.004 (ABNT, 2004) os resíduos “...resultam de atividades de origem industrial, doméstica, hospitalar, comercial, agrícola, de serviços e de varrição". Desse modo, é chamado de resíduos (ou lixo) tudo aquilo que um dia foi utilizado e por algum motivo não possui mais serventia. Segundo o censo de 2007 do Instituto Brasileiro de Geografia e Estatística - IBGE, a quantidade diária de lixo urbano coletado no Brasil é de 228.413 toneladas, o que representa $1,25 \mathrm{Kg}$ diários por cada um dos cerca de 182.420.808 habitantes do país e mais de $70 \%$ desses resíduos são lançados de forma irregular, na maior parte em lixões a céu aberto.

\subsection{DIFERENÇAS ENTRE LIXÃO E ATERRO SANITÁRIO}

Os lixões podem ser descritos como áreas sem nenhuma preparação para receber resíduos e assim evitar danos ao meio ambiente e a saúde da sociedade. De acordo com a ABNT (2004), os lixões são formas inadequadas de disposição final de resíduos sólidos, caracterizados pela simples descarga sobre o solo, sem medidas de proteção ao meio ambiente ou à saúde pública. Depósitos como estes não possuem nenhum tratamento e seu material em decomposição contamina a terra, os lençóis freáticos, o solo, água e o ar. Além desses problemas, os lixões também atraem animais e catadores, que se alimentam de resíduos orgânicos ou recolhem materiais recicláveis para venda. Já os aterros sanitários são empreendimentos desenvolvidos com critérios técnicos de engenharia e normas específicas que atendem as leis ambientais. Estas normas permitem o acondicionamento seguro dos resíduos e controlam a poluição ambiental. A ABNT (1997) define os aterros sanitários como:

[...] a técnica de disposição de resíduos sólidos urbanos no solo, sem causar danos ou riscos à saúde pública e à segurança, minimizando os 
impactos ambientais, método este que utiliza os princípios de engenharia para confinar os resíduos sólidos ao menor volume permissível, cobrindo-os com uma camada de terra na conclusão de cada jornada de trabalho ou à intervalos menores se for necessário.

Existe dois tipos de dificuldades para a implantação e operação de aterros sanitários:

- A técnica, que esbarra na falta de profissionais para atender a futura demanda imposta pela Política Nacional de Resíduos Sólidos; e

- A financeira, causada pelos altos custos de operação dos empreendimentos.

A financeira é o maior desafio das administrações porque um aterro sanitário pode consumir grande parte dos orçamentos públicos municipais. Entretanto, para esse último caso, a Política Nacional de Resíduos Sólidos prevê algumas alternativas para gestão dos recursos necessários a manutenção dos aterros sanitários.

\subsection{A POLÍtica nACIONAL de RESíduOS SÓlIDOS: LEI FEDERAL № 12.305, DE 2 DE AGOSTO DE 2010}

A nova lei, de caráter regulador, passa a ser aplicada às pessoas físicas e jurídicas que são direta ou indiretamente responsáveis pela geração de resíduos sólidos. De forma geral, a Política Nacional de Resíduos Sólidos zela pela responsabilidade de todos os municípios brasileiros aderirem ao programa; da necessidade de quantificação e caracterização dos resíduos; das responsabilidades dos geradores pelo acondicionamento dos resíduos dentre outros direitos e deveres. Dentre seus principais objetivos estão a proteção da saúde pública e da qualidade ambiental e a gestão integrada de resíduos sólidos. Para isso, proíbe a disposição dos resíduos em lixões, o que levará os municípios a adotarem solução técnicas mais adequadas para disposição e tratamento de resíduos, representadas nesse caso, pelos aterros sanitários. A lei ainda prevê que o acesso a recursos para limpeza urbana serão priorizados aos municípios que adotarem soluções consorciadas para seus sistemas de limpeza numa clara tentativa de incentivar a formação de consórcios municipais como os previstos pelos Planos Regionais de Gestão Integrada de Resíduos Sólidos, atualmente em desenvolvimento em diversas unidades federativas do país. O incentivo aos consórcios também possuem função estratégica uma vez que soluções consorciadas apresentam custos mais baixos quando comparada soluções individuais.

\section{METODOLOGIA DA PESQUISA}

Para o desenvolvimento dessa pesquisa utilizou-se inicialmente a metodologia de modelagem matemática com base em técnicas de regressão (Ayres, 2008) que consiste basicamente em aplicar algoritmos matemáticos para avaliar a tendência de comportamentos de dados. Essa modelagem foi utilizada para se obter os custos dos aterros sanitários em 
função da população, e o percentual do PIB empregado para disposição de resíduos em aterros sanitários.

Posteriormente com o uso do banco de dados dos municípios brasileiros se gerou um mapa onde pode-se observar em que faixa de utilização do PIB encontra-se cada município e baseado na análise feita anteriormente qual seria os municípios que possuem capacidade de sustentar um aterro sanitário individual.

A geração das informações foi baseada no banco de dados do IBGE com indicadores populacionais em conjunto com informações de aterros sanitários implantados em 126 municípios do país e para obtenção dos custos de operação de aterros sanitários foram realizadas pesquisas bibliográficas (contratos de prestação de serviços advindos de licitações públicas) e análise de dados históricos disponíveis "portais de transparência" de diversas prefeituras que possuem aterros sanitários. A localização dos municípios e respectivos aterros pesquisados são apresentados na Figura 1: 


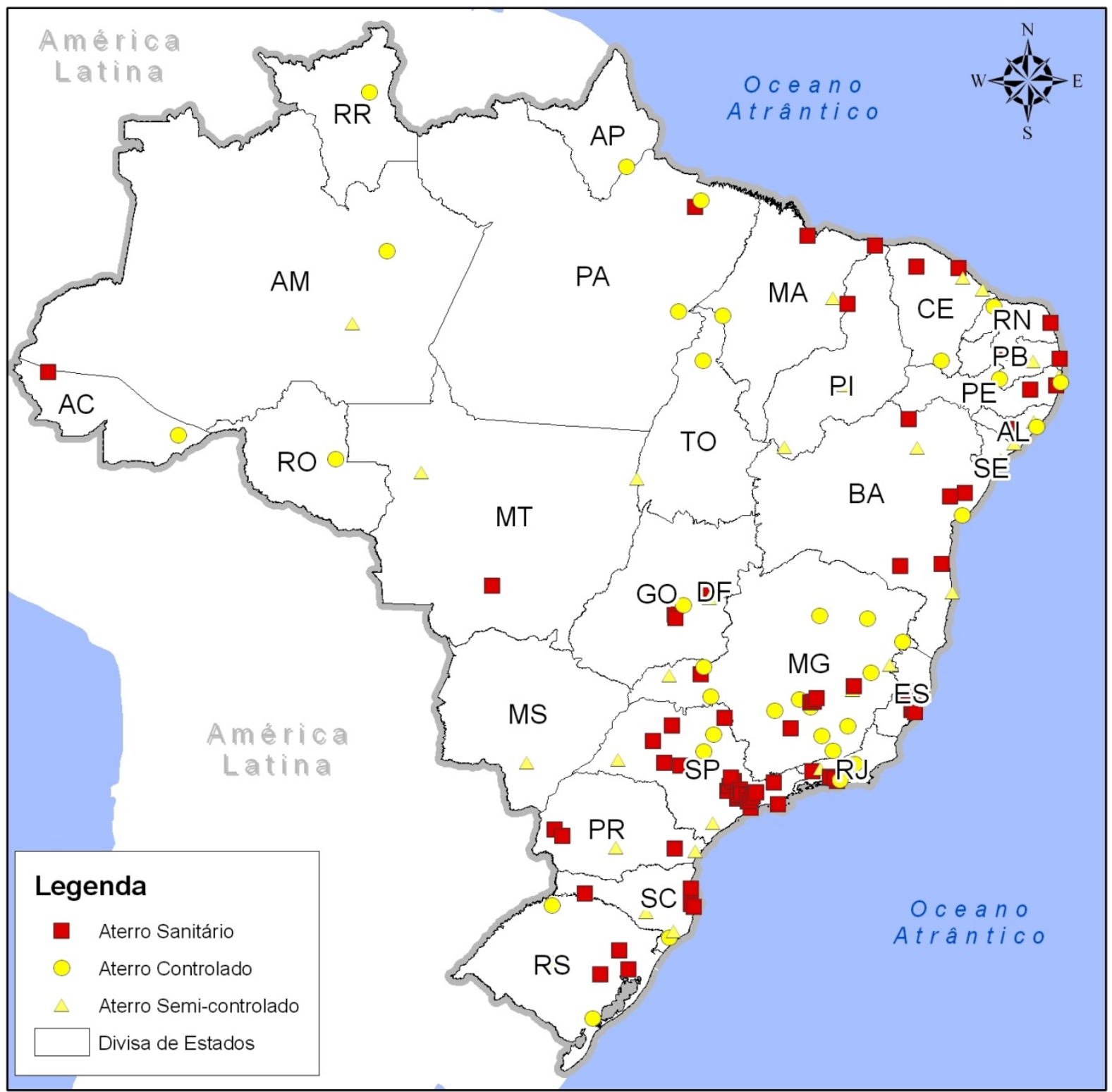

Figura 1: Mapa dos municípios com aterro sanitário

Fonte: adaptado de Silva, 2009.

O banco de dados com informações de custos em relação ao PIB municipal e população foi manipulado com os softwares Microsoft Excel XP e Statistica 6.0 da StarSoft. 0 Excel foi utilizado para montagem e compilação de bancos de dados, desenvolvimento de gráficos e funções necessárias desenvolvimento dos modelos e análises estatísticas.

\section{RESULTADOS}

\subsection{GERAÇÃO PER CAPTA DE RESÍDUOS}


Com base na população e da quantidade de resíduos que chegam em cada aterro pesquisado, determinou-se a geração per capta média de resíduos em torno de 740 (setecentos e quarenta) gramas por habitante/dia. Esse valor encontra-se é inferior do estimado pelo IBGE no censo de 2007 , que foi de $1,25 \mathrm{~kg} / \mathrm{hab}$.dia, no entanto, deve ser considerado que uma parte dos resíduos produzidos nas cidades não é destinada aos aterros sanitários como no caso de entulhos e outro resíduos classificados como inertes de acordo com a NBR 10.004 da ABNT. Dessa forma, para lançar no banco de dados de cada município a estimativa de geração de resíduos utilizou-se a Equação 1:

$$
Q=\frac{N \times 0,74 \mathrm{Kg} \times 26,09 \text { dias }}{1.000 \mathrm{Kg}} \quad(\text { Equação } 1)
$$

Onde:

$\mathrm{Q}=$ quantidade de resíduos que aportam a um aterro

$\mathrm{N}=$ população (hab);

\subsection{CUSTOS DE DISPOSIÇÃO DE RESÍDUOS EM ATERROS EM FUNÇÃO DA POPULAÇÃO}

A partir da base de dados de 126 aterros espalhados nas diversas regiões do Brasil, e sua respectiva população, estimou-se o custo de aterros em função da população como mostrado na Figura 2.

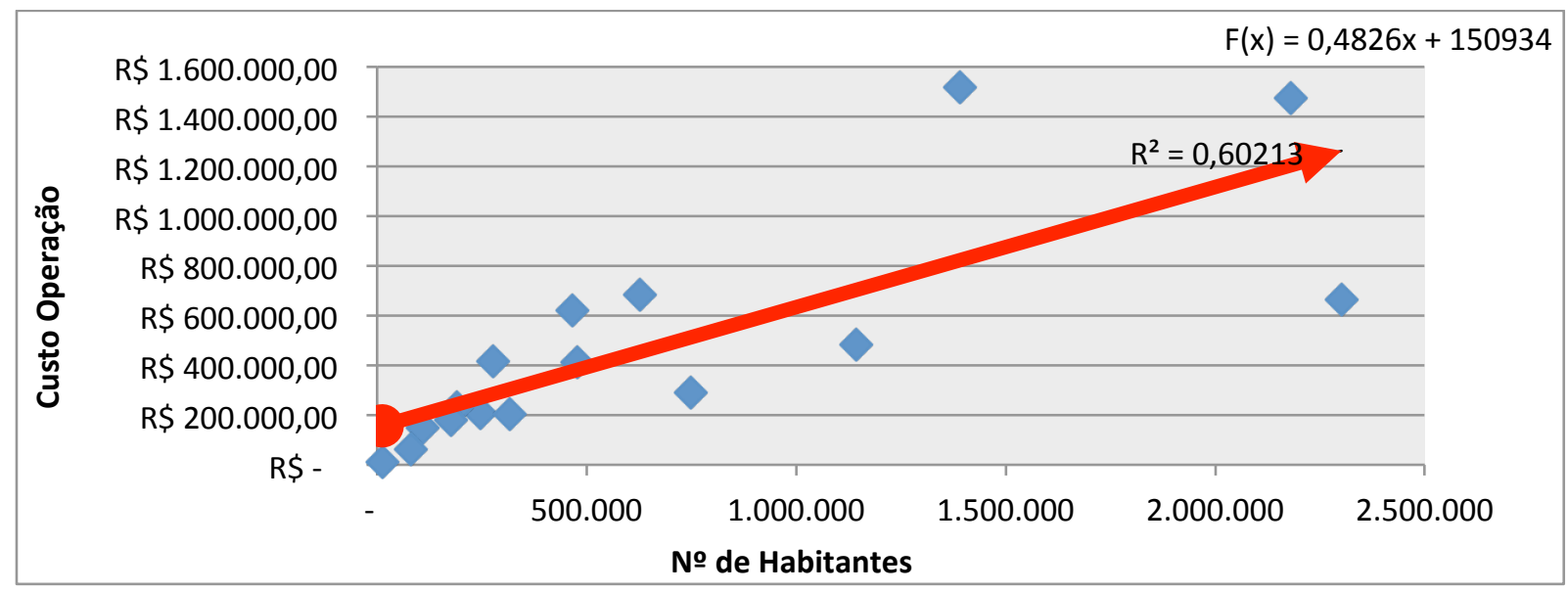

Figura 2: Gráfico de regressão linear do custo do aterro por numero de habitantes nas cidades pesquisadas. Fonte: Desenvolvido pelos autores.

Os resultados comportam-se como uma função linear positiva, ou seja, quanto maior a população, maiores os custos totais de operação dos aterros sanitários conforme relação mostrada na Equação 2.

$$
\mathrm{F}(\mathrm{x})=0,4826 \mathrm{X}+150934 \quad \text { (Equação 2) }
$$

Onde:

$\mathrm{F}(\mathrm{x})=$ representa o custo total de operação do aterro/mês em $\mathrm{R} \$$; 
X = número de habitantes da cidade;

Da Figura 2 podem-se identificar dois parâmetros básicos a serem considerados para a disposição de resíduos em aterros:

O custo mínimo para operação de um aterro de aproximadamente $R \$ 150.000$, o que corresponde a média dos custos administrativos fixos para o tipo de empreendimento; e

Quanto maior a população atendida por um aterro, menor o custo per capta mensal da disposição e tratamento dos resíduos, indo de $\mathrm{R} \$ 1,99$ para cidades com até 500.000 habitantes para $\mathrm{R} \$ 0,54$ para cidades com mais de 2.500 .000 de habitantes, por exemplo.

Dessa forma, observa-se que para a disposição de resíduos em aterros, quanto maior a população atendida menor será o custo por tonelada depositada no aterro. Dessa forma se pressupõe que o uso de consórcio entre municípios, tornará os custos de operação por tonelada disposta e tratada bem inferior ao uso com a disposição em aterros individualizados.

\subsection{IMPACTO DA DISPOSIÇÃO DE RESÍDUOS EM ATERROS EM FUNÇÃO DO PIB MUNICIPAL}

Confirmada na tese que aterros consorciados tornam-se mais baratos, procurou-se apresentar um cenário caso os municípios optassem por soluções individuais. A primeira fase foi a definição de um índice padrão a ser aplicado a todos os municípios brasileiros, sendo escolhido para isso o impacto dos custos dos aterros sobre o Produto Interno Bruto - PIB de cada município, a ser apresentado em porcentagem. Assim, quanto maior o valor desse índice, maior será o impacto dos aterros sobre as economias locais. Para coelho (2008), o PIB é a soma de todos os bens e serviços finais produzidos dentro do território econômico (de um país, estado ou cidade) independentemente da nacionalidade dos proprietários das unidades produtoras.

A segunda fase do estudo consistiu na determinação dos \% do PIB empregado em cada um dos 126 municípios que possuem aterro sanitário até o ano de 2008. O resultado está sintetizado na Figura 3: 
Figura 3: Histograma com o impacto dos custos de aterros sobre os PIB's dos municípios pesquisados. Fonte: Desenvolvido pelos autores

Observa-se na Figura 3 que:

O impacto médio dos custos do aterro sanitário sobre os PIB's municipais é de pouco mais de 6\%;

O desvio padrão para impacto dos custos do aterro sanitário sobre os PIB's é de aproximadamente $5 \%$.

O custo máximo de um aterro sanitário chega a 23\% do PIB municipal.

Ao considerarmos a média e o desvio padrão chega-se a conclusão que um município só poderá arcar com os custos de um aterro sanitário se este consumir até $23 \%$ do seu PIB. No entanto, como a curva normal e o agrupamento dos resultados nos indica, existem três tipos de cenários encontrados nos municípios pesquisados, o primeiro indo de $1 \%$ a $10 \%$, o segundo de $13 \%$ a $18 \%$ e o terceiro acima de $19 \%$ do uso do PIB. Esse agrupamento ou clusters em conjunto dos os parâmetros estatísticos como Média e desvio padrão informam que:

Municípios que utilizem até $6 \%$ do seu PIB com o tratamento de resíduos sólidos em aterros sanitários devem ser considerados como viáveis para o uso de soluções individualizadas; 
Municípios que utilizem até $12 \%$ do seu PIB com o tratamento de resíduos sólidos em aterros sanitários (média mais desvio padrão 1) devem ser considerados como parcialmente viáveis na adoção de soluções individualizadas; e

Municípios que utilizem mais $12 \%$ do seu PIB com o tratamento de resíduos sólidos em aterros sanitários devem ser considerados como pouco viáveis ou até mesmo como inviáveis, necessitando de soluções consorciadas para reduzir os custos.

A partir dessa constatação aplicaram-se esses parâmetros a todos os municípios brasileiros para obtenção dos resultados para um cenário nacional caso todos os municípios adotem soluções individualizadas para a disposição e tratamento de seus resíduos.

\subsection{IMPACTO DOS CUSTOS DA OPERAÇÃO DE ATERRO SANITÁRIOS INDIVIDUAIS PARA TODOS OS MUNICÍPIOS BRASILEIROS}

Para obtenção do impacto dos custos do aterro sanitário sobre os PIB's municipais de todos os municípios brasileiros aplicou-se as Equações 1 e 2 sobre o banco de dados do IBGE contendo a estimativa populacional de cada município do país. Os resultados foram novamente agrupados sob a forma de histograma, conforme o modelo apresentado na Figura 3 , gerando o histograma da Figura 4.

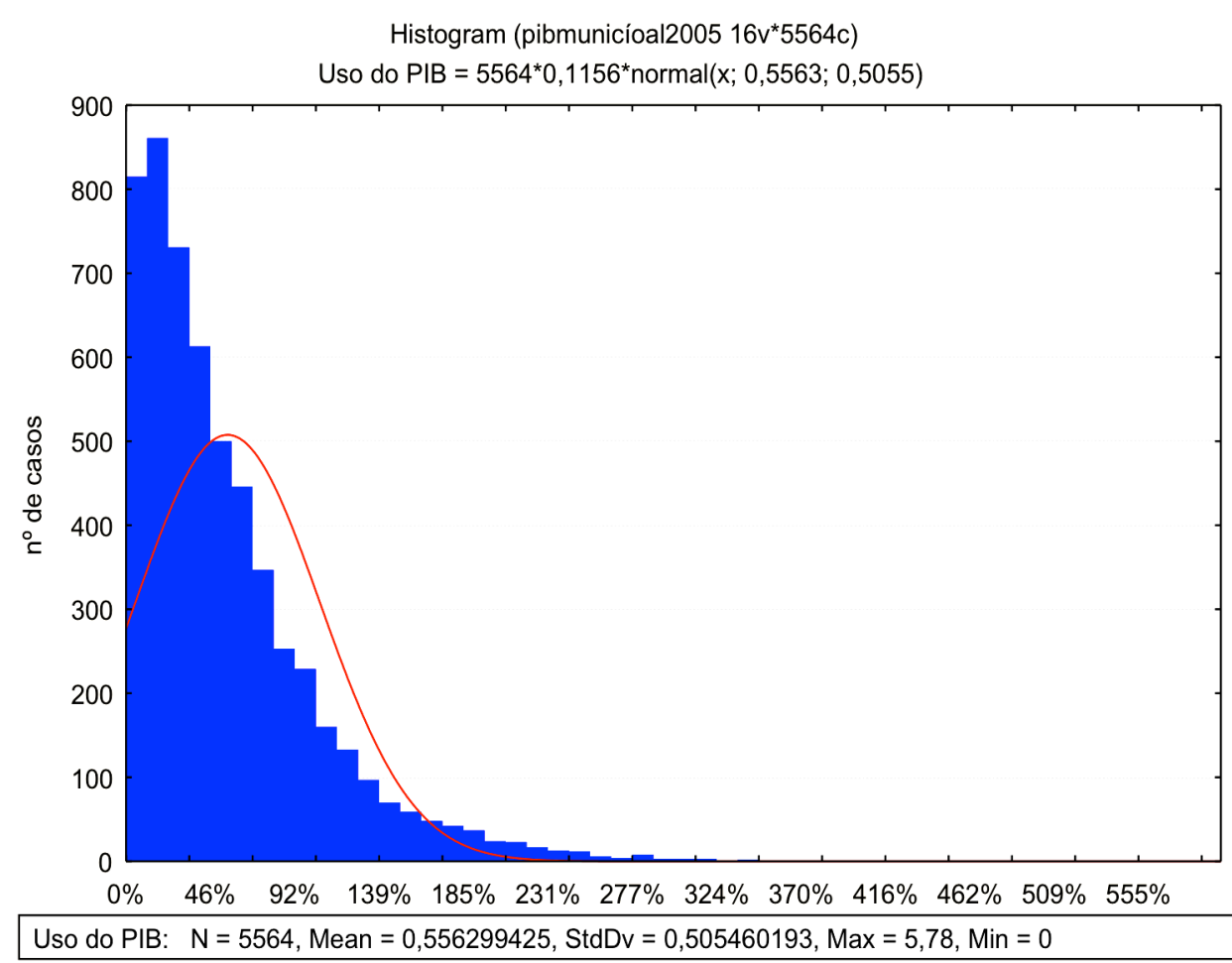

Figura 4: Histograma com o impacto dos custos de aterros sobre os PIB's nos municípios brasileiros. Fonte: Desenvolvido pelos autores 
O histograma apresentado na Figura 4 apresenta um comportamento exponencial e nos indica que:

Apenas 810 , ou cerca de $14 \%$ dos municípios brasileiros, teriam condições de manter aterros sanitários de forma individualizada tendo em vista que o \% do PIB usado para o pagamento do aterro é de até $12 \%$. Esses municípios são compostos na maior parte dos casos pelas capitais estaduais e outros pertencentes suas regiões metropolitanas ou ainda por sedes de pólos regionais com mais de 40.000 habitantes.

Se todos os municípios optassem por possuir aterros sanitários, o impacto dessa solução representaria o consumo médio de aproximadamente $55 \%$ dos PIB municipal, o que classifica tal cenário como inviável;

Quase $20 \%$ dos municípios teriam de gastar mais do que arrecadam para manter seus aterros sanitários em funcionamento.

Cabe lembrar nesse momento, que os resultados consideram apenas a operação dos aterros sanitários, estado desconsiderado os custos com limpeza urbana e transporte de resíduos.

\subsection{DISTRIBUIÇÃO ESPACIAL DA VIABILIDADE DO USO DE SOLUÇÕES INDIVIDUAIS EM TERRITÓRIO NACIONAL}

De modo a auxiliar na compreensão dos resultados descritos anteriormente optou-se por apresentar os dados em um mapa. Para elaboração do mapa os dados que geraram os resultados apresentados no histograma de Figura 4 foram inseridos no Arcview da Esri, versão 3.2, e associados a um banco da dados espacial presente no IBGE sob a forma de shapefile contendo os limites dos municípios Brasileiros. Para a legenda empregou-se as categorias "Viáveis" e "Parcialmente Viáveis" conforme parâmetros descritos anteriormente. Os resultados são apresentados na Figura 5. 


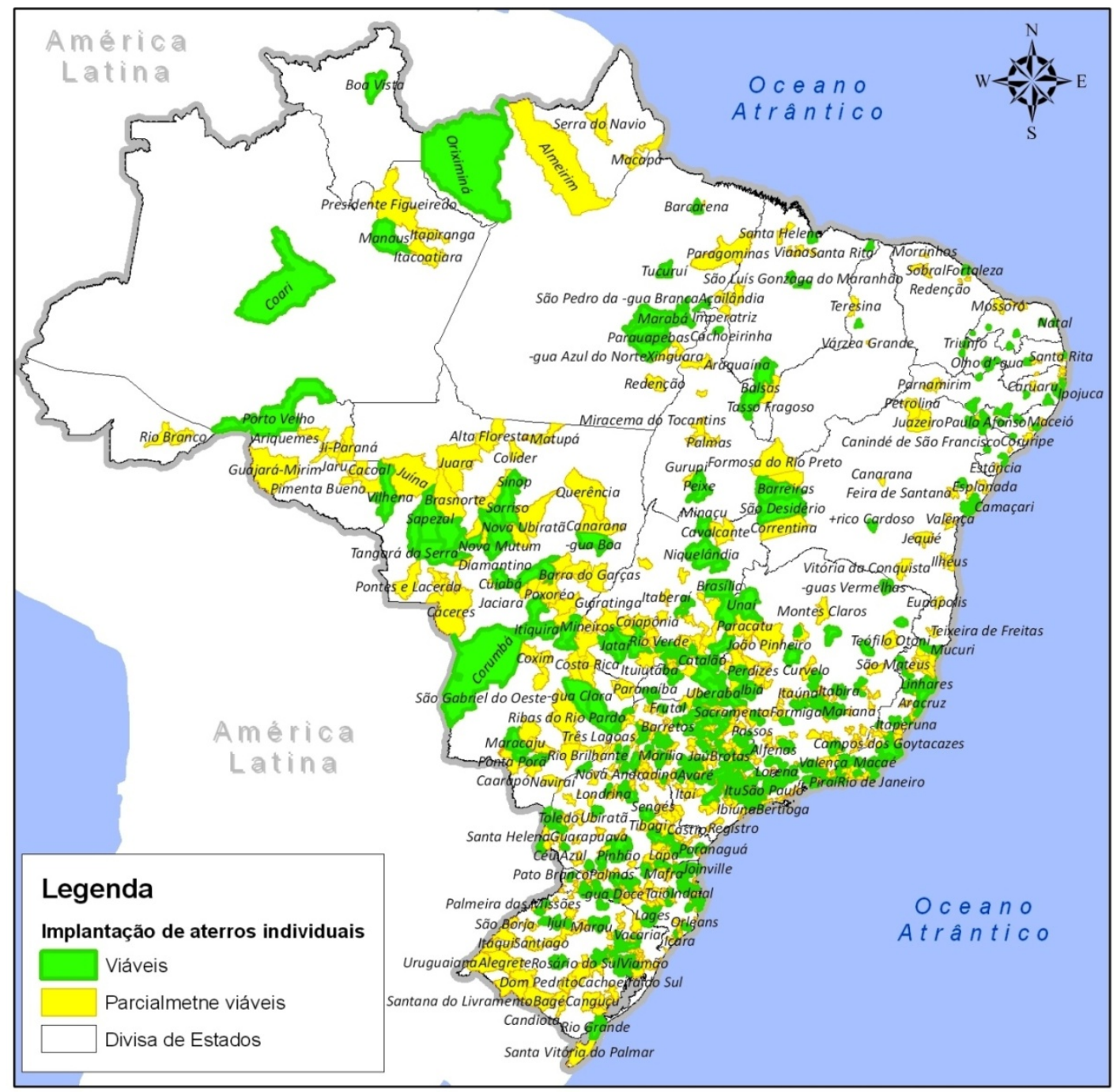

Figura 5: Distribuição da adoção de aterros sanitários individualizados para o Brasil. Fonte: Desenvolvido pelos autores

Avaliando-se o mapa é possível verificar que:

As regiões Sudeste, Sul e Centro-Oeste são as apresentam melhores condições de optar por aterros sanitários individualizados; e

As regiões Norte, Nordeste de Norte de Minas Gerais apresentam as maiores extensões contíguas de municípios sem capacidade de assumir o ônus de um aterro sanitário individualizado. A situação torna-se mais desfavorável à medida que nos afastamos do litoral onde estão as cidades mais populosas.

Os resultados também são compatíveis a realidade porque basta sobrepor as informações presentes nas Figuras 1 e 5 apresentadas nesse artigo para verificar que a maior parte os aterros sanitários existentes até o ano de 2008 estão em locais considerados viáveis ou parcialmente viáveis conforme verificado na Figura 6: 


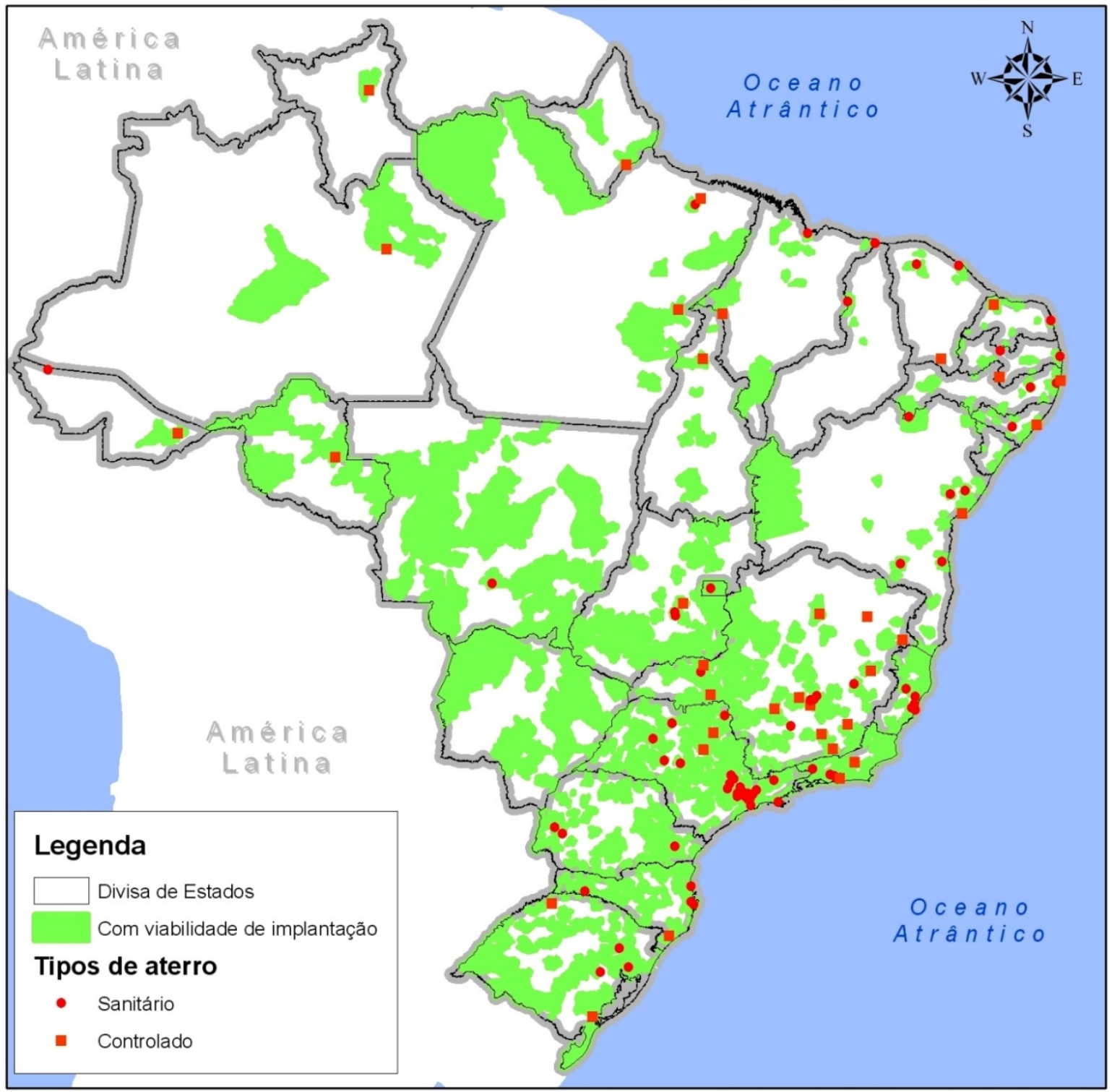

Figura 6: Distribuição da adoção de aterros sanitários individualizados para o Brasil. Fonte: Desenvolvido pelos autores

Dessa forma, considerarmos que o modelo elaborado corresponde aos dados observados, onde os aterros sanitários implantados atualmente, encontram-se em regiões onde a relação entre o custo do aterro e o percentual do PIB é inferior a $12 \%$.

\section{CONCLUSÃO}

A adoção de aterros sanitários individualizados é inadequada para a maior parte dos municípios brasileiros, pois consome uma parcela relevante de seus orçamentos. Dessa forma, uma das soluções é o uso de consórcios públicos de acordo com o preconizado pela Política Nacional de Resíduos Sólidos. Contudo, para avaliar os melhores arranjos entre municípios para a formação de consórcios há de se considerar a quantidade total da população a ser atendida e o impacto dos custos do aterro sobre as soma dos PIB's municipais 
com posterior rateio proporcional desses custos em relação ao montante de resíduos a serem dispostos e tratados em cada empreendimento. Assim, de acordo com os resultados encontrados nesse trabalho, é sugerido que a viabilidade econômica da disposição em aterros se dá para arranjos onde os custos sejam equivalentes no máximo $12 \%$ PIB's dos consórcios.

Para validar os consórcios também devem ser considerados os custos do transporte desses resíduos, de sua fonte geradora até o aterro, sendo necessário o uso de estudos de logística e a possível implantação de transbordos para baratear tais custos.

Os grandes desafios para os municípios, estados e governos federal será o desenvolvimento e manutenção sustentáveis dos consórcios a serem desenvolvidos no interior das regiões Norte, Nordeste e Norte de Minas-Gerais, onde na maior parte dos municípios apresentam relações custo de aterro/PIB's inviáveis caso optem por utilizar soluções individuais.

\section{REFERÊNCIAS}

1. Ayres, Ian. Super Crunchers: porque pensar com números é a nova maneira de ser inteligente. São Paulo, 2008.

2. Associação Brasileira de Empresas de Limpeza Urbana - ABRELPE. Panorama dos resíduos sólidos no Brasil. 2005. São Paulo.

3. Associação Brasileira de Normas Técnicas - ABNT, Norma Brasileira Regulamentada, NBR 8419. Apresentação de Projetos de Aterros Sanitários de Resíduos Sólidos Urbanos. Abril, 1992.

4. Norma Técnica Brasileira 10.004. 2004. São Paulo/SP, Brasil.

5. CÂMARA, Gilberto; CASANOVA, Marco A.; HEMERLY, Andrea S.; MAGALHÃES, Geovane; MEDEIROS, Cláudia . Anatomia de Sistemas de Informação Geográfica. Rio de Janeiro. 1996.

6. COELHO, Daniel Simões. 0 que é PIB?. 2008. Disponível em: http://www.academiaeconomica.com/2008/08/o-que-pib.html. Acesso em 01 nov 2010.

7. INSTITUTO BRASILEIRO DE GEOGRAFIA E ESTATÍ́stICA - IBGE. Censo 2000. Disponível em:http://www.ibge.gov.br . Acesso em: 15 Ago. 2010.

8. SILVA, Glauber Nóbrega. Aterros Sanitários no Brasil. 2009. Disponível em http://www.scribd.com/doc/30406318/Aterros-sanitarios-no-Brasil. Acesso em: 20 out 2010. 